\title{
BASES TEÓRICAS PARA UM PROJETO DE REVISÃO DE TRADUÇÕES, BUSCANDO O APRIMORAMENTO DAS PRODUÇÕES DE TRADUTORES E TRADUTORAS EM FORMAÇÃO
}

\section{Theoretical bases for a project of translation reviewing, focusing on the improvement of textual productions by translators in training}

DOI: $\underline{10.14393 / L L 63-V 35 n 2-2019-2}$

Daniel Alves*

\begin{abstract}
RESUMO: O artigo discute a revisão de textos traduzidos, sob uma perspectiva teórica, buscando promover a atividade como um processo comunicativo cujo objetivo principal é o aprimoramento da produção textual de tradutores e tradutoras em formação. Ao levantar a discussão sobre como promover a revisão em contextos de formação de tradutoras e tradutores, busca-se aqui estabelecer as bases teóricas para um projeto de intervenção pedagógica que busca se constituir como uma intervenção de efeito positivo para aprendizes, com foco na negociação de sentidos, buscando a compreensão de textos traduzidos dentro dos seus contextos de produção em um sentido amplo. A discussão se fundamenta em trabalhos como Leipnitz (2016), Ferreira (2018), e Mossop (2007) que discutem a revisão de textos traduzidos - e de Ruiz (1998) e de Morais e Ferreira (2006) - que discutem processos pedagógicos voltados para o aprimoramento das produções textuais de discentes.
\end{abstract}

PALAVRAS-CHAVE: Estudos da Tradução. Revisão de textos traduzidos. Formação de tradutores e tradutoras.

ABSTRACT: This paper fosters a theoretical debate on reviewing translated texts, focusing on the activity as a process of communication aimed at enhancing the textual production of translators in training. By shedding light on the issue, in contexts of education of translators, this paper aims at building a theoretical basis for a pedagogic project of positive intervention on the works of students, focused on processes of negotiation of meanings, and on understanding translated texts within their contexts of production in a broader sense. The discussion draws on works such as Leipnitz (2016), Ferreira (2018), and Mossop (2007) - on reviewing translated texts - and on Ruiz (1998) and Morais e Ferreira (2006) - on pedagogic processes aimed at enhancing the textual production of students.

KEYWORDS: Translation Studies. Reviewing translated texts. Translator's education.

* Doutor em Estudos da Tradução pela UFSC. Professor do curso de Bacharelado em Tradução da UFPB. ORCID: 0000-0002-3702-0895. E-mail: daniel(AT)cchla.ufpb.br 


\section{Introdução}

Este artigo nasceu da experiência de trabalhar com uma disciplina de prática de revisão de textos traduzidos com turmas de graduação, do curso de Bacharelado em Tradução da Universidade Federal da Paraíba. Oferecida a partir de 2016, a disciplina tem como objetivo principal levar discentes a desenvolverem suas habilidades de revisar textos traduzidos, aprimorando suas competências tradutórias e, em última instância, a se tornarem cada vez mais autônomos/as em seus trabalhos de produção textual.

Embora a experiência com as ofertas da disciplina tenha sido amplamente positiva, ao longo dos anos, dois problemas se mostraram recorrentes: i) o relativamente baixo número de referências teóricas, especialmente brasileiras, que abordassem a revisão de textos traduzidos de forma alinhada com a proposta do curso; ii) a expectativa, por parte de discentes, de que seriam trabalhados conjuntos fechados de regras rígidas - seja regras de equivalências unívocas entre línguas, seja regras gramaticais normativas na língua de chegada dos textos a serem revisados.

Este artigo visa a lidar com os dois problemas mencionados no parágrafo anterior: na primeira frente, aborda-se aqui, sob uma perspectiva teórica, como a revisão de textos traduzidos pode ser trabalhada como um processo de comunicação, no qual as interações entre revisores/as e tradutores/as têm por objetivo o aprimoramento da produção textual desses/as últimos/as. Na segunda frente, busca-se levantar a discussão sobre como promover a revisão em contextos de formação de tradutoras e tradutores, tratando-a como uma ação dialógica complexa, que se principia em uma ação de valoração acerca de um texto traduzido e que tem como objetivo se constituir como uma intervenção de efeito positivo para aprendizes.

Considerar o componente de valoração textual nas atividades de revisão não implica, de forma alguma, que este artigo lidará com relações de atribuição de notas ou de estabelecimento de níveis de aprovação/reprovação escolares. As relações (e as analogias) revisão-valoração-avaliação partem da ideia de que qualquer indicação de revisão em um texto traduzido, ou efetiva realização de uma revisão/correção textual, necessariamente parte do julgamento de que um texto, ou um segmento textual em específico, pode ser melhorado, esclarecido ou textualizado de forma diferente. 
Dentro da proposta aqui trabalhada, são estabelecidos diálogos com discussões que i) entendem textos como todos significativos, construídos a partir de interações humanas; ii) promovem a competência tradutória como um conhecimento especializado construído por meio da metarreflexão e da aplicação de estratégias e técnicas; e iii) promovem ideias de como "apontar caminhos que venham (...) a facilitar a escolha de estratégias de ensino que propiciem o desenvolvimento do[/a] aluno[/a] como produtor[/a] de textos escritos na escola e na vida" (MORAIS; FERREIRA, 2006, p. 66).

Para estabelecer esses diálogos, foram buscados trabalhos sobre a revisão de textos traduzidos dentro do campo disciplinar dos Estudos da Tradução e - quando necessário preencher lacunas teóricas percebidas nesse campo - trabalhos que discutem a produção e a avaliação de textos em contextos de ensino. Destacam-se aqui pesquisas como a de Leipnitz (2016) - que usa os trabalhos do grupo PACTE $(2003,2008)$ como referência - bem como de Ferreira (2018), de Mossop (2007), de Ruiz (1998) e de Morais e Ferreira (2006).

Para desenvolver a discussão, este artigo divide-se em quatro seções, contando com esta introdução, organizadas da seguinte maneira: a segunda seção, a seguir, aborda tipos e práticas de revisão, tomando como ponto de partida a norma ISO 17100 de 2015 e buscando concentrar este artigo na revisão enquanto forma de análise monolíngue do texto traduzido, evitando visões reducionistas que trabalham a produção de textos apenas em termos de certo versus errado. A terceira seção se concentra na revisão como forma de intervenção positiva, na qual são estimuladas a metarreflexão e o desenvolvimento da visão (auto)crítica do/a aprendiz, além da busca constante pela autonomia do/a discente. A quarta seção traz considerações, encaminhamentos e desenvolvimentos futuros, trabalhando a partir das reflexões de Ruiz (1998) e tentando estabelecer propostas de ações de revisão de textos traduzidos em contextos de formação.

\section{Tipos e práticas de revisão}

No atual cenário, não existem regulamentações rígidas no que tange às partes linguística e textual da prestação de serviços de tradução no país ${ }^{1}$, de forma que boa parte das

\footnotetext{
${ }^{1}$ Não me refiro aqui a quaisquer legislações comerciais e trabalhistas - daí, portanto, a especificação sobre as partes linguística e textual das prestações de serviços de tradução.
} 
decisões de como proceder com esses serviços cabe às próprias empresas e prestadores/as de serviços. Em se tratando da revisão de textos traduzidos, observam-se diferentes práticas de mercado - que vão desde um extremo de não preocupação com a realização de revisões dos textos a serem publicados até o outro extremo em que as decisões do/a revisor/a são supervalorizadas e se sobrepõem a quaisquer escolhas do/a tradutor/a (que, em alguns casos, sequer tem espaço para questionar as revisões ou para discutir seu processo de construção textual).

Não se busca com este artigo tentar impor práticas ao mercado, tampouco estabelecer quaisquer bases para futuras regulamentações. Busca-se aqui, como apontado desde a introdução deste texto, fomentar as discussões sobre a revisão de textos traduzidos como um processo que visa a um aprimoramento da produção textual de tradutores e tradutoras em formação.

A própria concepção de revisão a ser trabalhada precisa ser inicialmente definida, uma vez que o conceito de revisão pode abranger diferentes operações que - embora tenham o objetivo comum de melhorar a qualidade de um dado texto - podem ser vistas como ações heterogêneas. Um ponto de partida para construir essa concepção pode ser tomado a partir da norma ISO 17100 de 2015. Trata-se de uma norma que especifica requisitos para os mais diversos aspectos que afetam a qualidade e a realização de serviços de tradução, abrangendo desde etapas iniciais (como processos de pré-produção) até etapas finais (como realização de controle de qualidade e arquivamento de trabalhos antigos). Para a norma ISO 17100 de 2015, são quatro os âmbitos de revisão pelos quais um texto traduzido pode passar, a saber:

1) Check Primeiro âmbito de revisão, realizado pelo/a tradutor/a ao examinar sua produção textual na língua de chegada (texto de chegada);

2) Revision...................Etapa de análise bilíngue do material, realizada por uma pessoa que não o/a tradutor ao examinar a adequação entre texto de chegada e de partida, em relação aos propósitos da tradução;

3) Review................... Análise monolíngue do texto traduzido, com vistas a avaliar se o texto de chegada está adequado aos propósitos pretendidos; e

4) Proofreading .............Âmbito final da revisão do texto de chegada, com vistas a identificação e correção de problemas, antes do envio para impressão. 
Ainda que alguns pontos da norma sejam passíveis de problematizações - inclusive no que tange aos limites entre cada etapa das tarefas de revisão, como aponta Leipnitz (2016, p. 177) ao afirmar que, mesmo quando não cabe ao/à revisor/a tarefa de retomar o texto de partida e cotejar tradução e texto fonte, muitas vezes a ação é necessária para se compreender o texto traduzido -, trata-se de uma referência importante para este artigo por permitir a delimitação das discussões em torno do processo de revisão como review.

Tal delimitação tem como propósitos a) evitar centrar discussões em posturas prescritivistas de equivalência entre texto de partida e texto de chegada; b) permitir adotar uma abordagem mais compreensiva em relação aos textos a serem revisados, considerandoos como todos significativos; c) promover visões que entendam processos de construção de significados a partir de textos em relação tradutória, evitando o estabelecimento de sistemas simplistas de certo versus errado. Em resumo, a partir dessa delimitação, estimula-se aqui uma modalidade de revisão que privilegia uma atenção global a processos de produção de significados, em detrimento das modalidades que se concentram na busca de erros textuais superficiais.

Um estudo de caso interessante, por se alinhar à visão proposta no parágrafo anterior e por lidar com as contribuições da revisão de textos traduzidos para o desenvolvimento da competência tradutória de aprendizes é apresentado por Leipnitz (2016). Nele, a autora discute a atividade de revisão da tradução "Comandantinhos" 2 (baseada no texto fonte "Befehlerles"). Especificando a revisão como forma de fazer com que o texto traduzido seja mais "fluente, coeso e coerente com a língua e a cultura alvo" (LEIPNITZ, 2016, p. 177), a autora apresenta o método tradutório adotado para a produção do texto "Comandantinhos", justificando as escolhas textuais e mostrando as ferramentas e estratégias usadas, bem como os conhecimentos adquiridos e contribuições da tarefa para a formação das tradutoras envolvidas, com destaque para o "gerenciamento de todo o processo de revisão, num trabalho de equipe" (LEIPNITZ, 2016, p. 180). A questão das subcompetências necessárias para a realização de revisões também é tratada pela autora, que as compara àquelas necessárias para a realização

2 A tradução 'Comandantinhos' também foi publicada na Revista Graphos, podendo ser acessada em: http://www.periodicos.ufpb.br/ojs/index.php/graphos/article/view/32166/16710. Acesso em: 02 out. 2018. 
de traduções, incluindo subcompetências estratégica, extralínguística, instrumental e de conhecimentos em tradução.

Ferreira (2018), por sua vez, apresenta uma metarreflexão também desenvolvida a partir da tarefa de tradução e revisão mencionada no parágrafo anterior (do texto "Comandantinhos", com base no texto fonte "Befehlerles"). A autora discorre sobre a tarefa de revisar o conto, apresentando um ponto de vista discente acerca da tarefa e das competências necessárias para o seu desenvolvimento. Para este artigo, interessa especialmente a observação de Ferreira (2018, p. 10) de que "a revisão de tradução é considerada uma atividade a ser realizada pelo[/a] tradutor[/a] profissional, embora ainda tenha sido pouco estudada e pesquisada". A autora fundamenta sua observação acerca dessa lacuna acadêmica sobre trabalhos relativos à revisão de textos traduzidos, apontando, por exemplo, que nas edições de 2013 e de 2016 do Encontro Nacional de Tradutores ${ }^{3}$, apenas duas propostas de trabalhos se debruçaram sobre o tema. A autora também se apoia em Robert $(2008)^{4}$ para relacionar o baixo número de trabalhos específicos sobre revisão às diferentes abordagens e terminologias sobre o tema.

Esse número de abordagens e terminologias acerca da revisão de textos traduzidos também pode ser notado em discussões como a de Hewson (2011), por exemplo, que lida com avaliação da qualidade de traduções ${ }^{5}$. Hewson (2011) abre as discussões de seu livro fazendo a distinção entre três termos: i) análise (analysis); ii) avaliação pedagógica (evaluation); e iii) crítica (criticism). Embora os três termos tenham semelhanças - no sentido de todos envolverem algum tipo de valoração sobre traduções - há diferenças no tipo de objetivo e de intervenção que eles implicam. O autor se baseia em McAlester (1999) ${ }^{6}$ para fazer a divisão

\footnotetext{
3 Promovido pela Associação Brasileira de Pesquisadores em Tradução (ABRAPT).

${ }^{4}$ ROBERT, Isabelle. Translation revision procedures: An explorative study. Translation and Its Others. Selected Papers of the CETRA Research Seminar in Translation Studies 2007, 2008. Disponível em: https://www.arts.kuleuven.be/cetra/papers/files/robert.pdf. Acesso em: 8 mar. 2018.

5 Para mais discussões sobre avaliação da qualidade da tradução (TQA - translation quality assessment), recomendo, além de Hewson (2011), citado no corpo do texto, o trabalho de Zehnalová (2013) - referência a seguir:

ZEHNALOVÁ, Jitka. Tradition and Trends in Translation Quality Assessment. In: ZEHNALOVÁ, Jitka; MOLNÁR, Ondřej; KUBÁNEK, Michal. Tradition and Trends in Trans-Language Communication. Olomouc: Palacký University, 2013.

${ }^{6}$ McALESTER, Gerard. The Source Text in Translation Assessment." GUNILLA M. Anderman and MARGARET Rogers (Ed.) Word, Text, Translation: Liber Amicorum for Peter Newmark. Clevedon: Multilingual Matters, 1999.
} 
entre os três, apontando que o primeiro está relacionado a análises do texto traduzido, em função do seu contexto de produção, sem implicar julgamentos de valor; o segundo é mais limitado a questões de ensino, envolvendo atribuição de notas; e o terceiro envolve atos interpretativos, voltados para a produção de discussões que elucidem o quadro interpretativo originado pelo texto fonte.

Dentre os trabalhos levantados que abordam a revisão de textos traduzidos nos termos previstos para esta discussão, destaca-se o livro de Mossop (2007). Nele, o autor apresenta um guia de princípios, voltado para tradutores e tradutoras - tanto profissionais quanto em formação - que pretendem revisar textos escritos por outrem ou melhorar suas habilidades de escrita e de autorrevisão. Trabalhando com as noções de edição e de revisão - abordandoas como atividades relacionadas que, embora sejam diferentes, têm áreas de sobreposição -, Mossop (2007) busca fomentar estratégias de leitura crítica de textos, que permitam i) a identificação de uma ampla gama de possíveis pontos a serem textualmente melhorados e ii) a tomada de decisões de correção que levem a uma melhora do texto escrito - o que vai incluir desde a correção de erros tipográficos até a correção de trechos em prol da consistência argumentativa, passando pela adequação a características do gênero textual em questão e organização lógica de argumentos.

Sem se apresentar como um guia de referência, livro de exercícios ou conjunto de regras do tipo certo versus errado, Mossop (2007) promove a importância da reflexão crítica, da análise de cada texto dentro de seu contexto de produção e de leitura, e do desenvolvimento de estratégias e princípios de correção - em detrimento da adoção de regras fechadas e simplistas. Dentre as discussões apresentadas por Mossop (2007), a que mais interessa a este artigo - sem desmerecer suas discussões sobre a função de editor/a de textos, sobre revisão estilística, estrutural, ou de conteúdo - diz respeito à tarefa de revisão de textos de outrem ("revising the work of others", nas palavras do autor).

Nessa relação de revisão de textos de outrem, Mossop (2007) discute alguns fatores que podem afetar a produção e o resultado das atividades de revisão empreendidas. Dentre esses fatores, Mossop (2007) dá destaque à gama de relações interpessoais e assimetrias que podem ser construídas entre autores/as e revisores/as e ao aspecto humano do trabalho. A respeito das relações entre autor/a e revisor/a, Mossop apresenta uma escala que vai desde 
situação de menor assimetria (em que estão em níveis hierárquicos semelhantes, como a revisão de textos entre colegas, por exemplo), até as situações de maior assimetria (em que autor/a e revisor/a estão em níveis hierárquicos diferentes, como relações chefe-funcionário/a, estudante-supervisor/a, por exemplo). Em relação ao elemento humano, Mossop (2007) discute questões como orgulho do trabalho, posturas defensivas em entender sugestões de revisão como críticas pessoais, dificuldade em receber críticas, etc. Esses fatores, como aponta o autor, podem afetar significativamente a forma como revisões são feitas e os resultados que elas geram.

Ao levantar a discussão, inscrevendo-a no âmbito da formação de tradutores e tradutoras, este artigo também busca diminuir o espectro de fatores que afetam o processo de revisão. Embora o contexto (da formação de tradutores e tradutoras) não seja livre de assimetrias, tampouco isento das reações humanas negativas que são discutidas por Mossop (2007), trata-se aqui de um ambiente que tende a ser mais favorável a processos de comunicação e metarreflexão (em comparação com ambientes comerciais/profissionalizados) e a abrir, por sua própria construção social, mais espaços para ações de aprendizagem e aprimoramento.

A próxima seção segue abordando a revisão em contextos de formação, mas tentando mitigar algumas das lacunas teóricas sobre a revisão de textos traduzidos e refletir sobre concepções de linguagem e de erro, e como essas concepções podem influenciar na revisão enquanto forma de aprimoramento da produção textual.

\section{Da revisão como forma de intervenção positiva}

Ainda há lacunas teóricas sobre o processo de revisão de textos traduzidos promovido como uma forma de comunicação, cujo foco é o aprimoramento da produção textual de tradutores e tradutoras em formação. Tentando contribuir para preencher um desses espaços, buscaram-se aqui discussões sobre ensino da escrita e avaliação de textos escritos. Embora o contexto de formação de tradutores e tradutoras seja bastante diferente do contexto de ensino da escrita, as discussões têm semelhanças (desde que feitas as devidas considerações), uma vez que ambas têm, em última instância, foco na busca por meios de intervir positivamente na produção textual de aprendizes. 
Ruiz (1998) e Morais e Ferreira (2006) lidam com a correção de redações na escola, promovendo o caráter processual da construção de textos e buscando o aprimoramento da produção textual de aprendizes - ambos condizentes, portanto, com a abordagem buscada neste artigo. Ruiz (1998, p. 2) enfatiza que processos de produção de esboços, rascunhos e rasuras são parte fundamental da escrita e defende que se trabalhem ações de correção como ferramentas capazes de levar "a uma escrita qualitativamente melhor, por parte do aluno", funcionando como "interferência[s] efetivamente positiva[s] no processo de aquisição da escrita desse aluno". Ao passo que Morais e Ferreira (2006) promovem, como ideal pedagógico, desenvolver a capacidade do/a aluno/a de "refletir sobre o texto que escreveu, de reescrevêlo, de analisá-lo e, assim, melhorá-lo" e não de, simplesmente, escrever um texto "certinho quanto à ortografia e gramática" (MORAIS; FERREIRA, 2006, p. 66).

Dentre os pontos que norteiam o trabalho de Ruiz (1998), destacam-se aqui: a) quais são as concepções de linguagem adotadas na correção de textos; b) quais são os tipos de correção promovidos; e c) como a revisão dos textos escritos ocorre, de que forma a interação é construída e que tipo de intervenção ela promove. O primeiro desses três pontos diz respeito às concepções de texto e de infração/erro textual a serem trabalhadas. Na visão desenvolvida pela autora, textos são entendidos como realizações linguísticas, de qualquer tamanho, que façam sentido para participantes em uma determinada situação de comunicação ${ }^{7}$. Subjacentes a essa conceituação de texto estão os princípios de textualização da Linguística Textual ${ }^{8}$ que, como bem discute Costa Val (2003), não são elementos imanentes ao texto, mas construídos nas situações de interação que se desenvolvem a partir de textos.

Ao trabalhar com essa concepção de linguagem, coloca-se em primeiro plano o fato de a comunicação humana ser dependente dos seus contextos de uso e da cooperação

\footnotetext{
${ }^{7}$ Embora outra das características associadas à concepção de texto seja a de que essas realizações linguísticas podem estar em qualquer ponto da escala entre o oral e o escrito, tanto na discussão de Ruiz (1998) quanto na discussão aqui apresentada sobre revisão de textos traduzidos, são trabalhados apenas textos na modalidade escrita (independentemente de haver, nesses textos, traços de oralidade).

${ }^{8}$ Refiro-me aqui aos sete princípios de textualização, discutidos por Costa Val (2003), a saber: 1) Aceitabilidade; 2) Coerência; 3) Coesão; 4) Informatividade; 5) Intencionalidade; 6) Intertextualidade; e 7) Situacionalidade. Para mais discussões sobre esses princípios e como eles se constroem nas situações de interação, recomendo a leitura de Costa Val (2003), indicada nas referências deste artigo.
} 
desenvolvida entre interactantes. Como destaca Ruiz (1998, p. 30), ganha preponderância, nessa visão,

(...) o papel que desempenham as diversas facetas do ato comunicativo, como as intenções do falante, o jogo de imagens recíprocas (...), o conhecimento partilhado pelos interactantes, as inferências, o conhecimento de mundo e os próprios elementos lingüísticos. Pensar o texto enquanto uma ocorrência lingüística significa concebê-lo verbalmente, numa dimensão sintática (gramatical), onde a integração das formas da língua adquire papel fundamental.

A partir dessa concepção, Ruiz (1998) defende que textos não sejam entendidos como estruturas acabadas, mas como processos construídos a partir das interações que eles promovem. Uma implicação importante desse entendimento para a revisão de textos é que o conceito de problema ou infração textual deixa de ser definido apenas com base no texto (enquanto produto), e passa a ser observado em função da situação de textualização (da construção do significado por meio da leitura) e de possíveis estranhamentos que sequências linguísticas possam causar no público receptor. A revisão passa, assim, a ser vista como uma das fases do processo de construção de um texto, tratando-se, portanto, de uma tarefa coletiva, em que as participações dialógicas do/a aluno/a e do/a revisor/a têm igual importância.

Tratando sobre tipos de correção e relacionando-os com os diferentes níveis de reflexão do/a professor/a (ou do/a revisor/a) sobre a linguagem, Ruiz (1998) defende que as retextualizações das produções discentes sejam guiadas por uma abordagem textual-interativa. Descrevendo essa abordagem como aquela realizada por meio de comentários mais longos feitos no espaço que a autora denomina como pós-texto (por vir na sequência ao texto do aluno) - cujas funções básicas, segundo Ruiz (1998, p. 67) são

(...) falar acerca da tarefa de revisão pelo[/a] aluno[/a] (ou, mais especificamente, sobre os problemas do texto), ou falar, metadiscursivamente, acerca da própria tarefa de correção pelo[/a] professor[/a].

Nessa abordagem de correção textual-interativa, como Ruiz (1998) destaca, as indicações de revisão buscam não apenas apontar problemas e erros na superfície textual, mas também reforçar aspectos positivos, sempre promovendo a metarreflexão sobre a produção textual discente e sobre os diferentes modos de construir mensagens e atitudes comportamentais em relação ao próprio trabalho, como a autocrítica e a constante busca pelo desenvolvimento autônomo de mecanismos para a (auto)avaliação e o (auto)aprimoramento. 
Dentre os pontos que norteiam o trabalho de Morais e Ferreira (2006) destaca-se aqui justamente a promoção da autonomia como ideal pedagógico - com vistas a extrapolar os limites da revisão enquanto tarefa focada em um texto específico e "[propiciar] o desenvolvimento do aluno como produtor de textos escritos na escola e na vida" (MORAIS E FERREIRA, 2006, p. 66). Ao trabalhar as competências para produzir textos, como defendem Morais e Ferreira (2006), busca-se, em última instância, despertar o interesse de alunos e alunas em desenvolver seus próprios dispositivos didáticos, reconhecendo características que levam ao sucesso de suas produções textuais e internalizando mecanismos para construir textos cada vez melhores.

Também privilegiando a interação por meio de processos argumentativos, Morais e Ferreira (2006) ressaltam a necessidade de aprendizes terem clareza sobre o gênero textual com o qual trabalham em cada produção textual, entendendo os propósitos comunicativos do texto, as características do público alvo e o espaço de circulação do texto produzido. Para os autores, é a partir da identificação dessas características que aprendizes poderão "do ponto de vista da textualidade e da convencionalidade da escrita (obediência à ortografia), ao emprego da norma prestigiada, (...) alcançar, de modo mais eficaz, o objetivo junto ao destinatário-leitor" (MORAIS; FERREIRA, 2006, p. 74).

Discutindo as formas como tradicionalmente se avaliam produções textuais, Morais e Ferreira (2006) destacam dois polos opostos: i) um no qual se hipervalorizam correções na superfície do texto - em outras palavras, consideram-se como boas produções textuais que simplesmente não apresentam problemas de ortografia, segmentação das palavras, emprego de maiúscula e pontuação -; ii) outro no qual são valorizados aspectos mais complexos de uma produção textual, como originalidade, capacidade de comunicação e adequação do texto aos seus propósitos pretendidos. Embora Morais e Ferreira (2006, p. 78) não menosprezem o primeiro polo, classificando o exame de aspectos normativos como chave para o acompanhamento dos progressos de alunos/as, os autores defendem a importância em "diagnosticar também os avanços e lacunas que dizem respeito ao domínio da textualidade" por parte de aprendizes.

Para Morais e Ferreira (2006), é apenas a partir de análises dos textos que alunos/as foram efetivamente capazes de produzir que se pode ajudá-los/as a melhorar. Assim, a 
modalidade de revisão textual que eles promovem só é possível a partir de uma abordagem pragmática - não sendo produtivas propostas prescritivistas, que apenas estabelecem visões duais (do tipo certo versus errado), sem considerar a realidade da produção textual de cada aprendiz - , ou, como colocam os autores, é apenas pela análise de textos efetivamente produzidos por aprendizes que

poderemos saber o que nossos alunos[/as] já internalizaram (sobre a linguagem dos diferentes gêneros textuais e sua notação), e identificar o que Ihes falta (re)construir em suas mentes, para poder escrever textos melhores. Essas informações nos ajudarão a planejar nossa intervenção na etapa de revisão - reelaboração das versões iniciais e no planejamento de futuras situações de produção de textos. (MORAIS; FERREIRA, 2006, p. 78-9)

A próxima seção mantém a discussão sobre como promover revisões, buscando o aprimoramento de aprendizes, inspirando-se a partir da proposta de Ruiz (1998) de 'como (não) corrigir redações na escola' e apontando desenvolvimentos futuros para este trabalho.

\section{Encaminhamentos e desenvolvimentos futuros}

De forma análoga ao trabalho de Ruiz (1998), o artigo aqui apresentado nasceu de um questionamento sobre como promover a revisão de textos traduzidos, estimulando tradutores e tradutoras em formação a produzir textos cada vez melhores. Acompanhando, portanto, a linha de raciocínio da autora, este artigo se conclui com um questionamento sobre como buscar intervenções produtivas, estimulando a autorreflexão e a autonomia de discentes.

Como apontado ao longo desse texto, o tipo de ação pedagógica aqui buscado só é possível por meio de diálogos entre revisor/a e tradutor/a em formação - sendo viável apenas a partir de uma modalidade de interação que toma, como ponto de partida, o entendimento de relações complexas de construção de significados a partir de textos traduzidos (sem partir de posturas prescritivas que entendem tradução apenas sob uma dualidade maniqueísta).

Propõe-se aqui buscar a revisão - e as retextualizações que ela implica - como processos inerentes à produção de traduções, evitando, tanto quanto possível, relações de assimetria e reações negativas por parte das pessoas envolvidas (como, por exemplo, posturas defensivas em relação às propostas de revisões e reformulações textuais). O contexto de formação de tradutores e tradutoras se mostra, portanto, ideal nesse sentido - por ser um 
espaço que, por sua própria função social, é dedicado à promoção de aprimoramentos discentes por meio de tarefas, diálogos e metarreflexões.

Pelo viés eminentemente teórico adotado neste artigo, não foram aqui realizados estudos de caso ou analisados exemplos de revisão. Buscou-se aqui dar visibilidade a uma tarefa pouco discutida, mas de grande importância, considerando os espaços de práticas tradutórias. Ao buscar essa visibilidade, este texto salienta a revisão como uma atividade profissional recorrente para tradutores e tradutoras profissionais (ainda que nem sempre bem remunerada, tampouco reconhecida) e que requer conhecimentos e competências específicos para uma boa reflexão.

Ao promover a revisão como uma atividade de valoração, cujo principal objetivo é o aprimoramento das produções textuais de discentes, merece destaque a proposta de Ruiz (1998), que propõe a adoção de uma abordagem funcional, ou textual discursiva, que enxerga "a língua como atividade (...) imersa num universo contextual repleto de relações de múltiplas ordens" (RUIZ, 1998, p. 187). Por meio dessa abordagem, segundo a autora, é possível trabalhar questões macroestruturais na revisão, priorizando alterações na forma do dizer e entendendo essas alterações em função de suas condições de produção.

Desenvolvimentos futuros deste trabalho envolvem:

i) conduzir um projeto de intervenção pedagógica semelhante ao apresentado em Leipnitz (2016), mas em escala maior do que a deste último, que busque trabalhar com tradutores e tradutoras em formação, propondo tarefas de revisão de textos traduzidos, estipulando desde as diretrizes para o texto traduzido até os parâmetros para valorar o sucesso comunicativo desse texto;

ii) verificar em que medida esse tipo de intervenção pode influir (positivamente ou não) nas reescritas resultantes das revisões, trabalhando de forma mais longitudinal e observando os desenvolvimentos das competências tradutórias de aprendizes;

iii) desenvolver discussões sobre os diferentes papeis de revisão desenvolvidos na relação entre professores/as e tradutores/as em formação (incluindo questões de assimetria que incluem professor/a como revisor/a; tradutor/a em formação como revisor/a do trabalho de outros discentes e tarefas de autorrevisão). 
A proposta de intervenção pedagógica (de revisão de traduções, com base em fundamentos da Linguística Textual) não visa a mera aferição de relações unívocas de tradução, tampouco o domínio de regras pré-estabelecidas, mas tem foco na negociação de sentidos, buscando a adequação da leitura dos textos traduzidos aos seus contextos (e propósitos) de produção.

Duas posturas a serem desenvolvidas dentro dessa prática de abordagem de textos escritos são: i) atenção aos problemas de natureza global dos textos e ii) a busca pela inserção do/a tradutor/a em formação no universo discursivo do texto traduzido, com foco nos gêneros textuais e nos diferentes fatores que podem afetar as escolhas tradutórias.

Tentando antever alguns desafios da proposta, pode-se também buscar inspiração na discussão de Ruiz (1998) - que, embora tenham-se passado duas décadas desde o trabalho da autora, continuam atuais no quadro pedagógico no país. Um primeiro desafio está relacionado aos hábitos de ensino da linguagem no país, que, de uma forma geral, ainda estimulam o domínio de regras normativas em detrimento das reflexões sobre a linguagem e sobre as diferentes formas de construir mensagens.

Um segundo desafio está nas maiores cargas de trabalho implícitas à proposta de trabalhar com a revisão buscando compreensões mais globais de textos e tentando empreender ações individualizadas de melhoria na produção textual - considerando que essas ações individualizadas também implicam um envolvimento maior de todas as partes envolvidas (seja do/a revisor/a, do/a professor/a ou do tradutor ou da tradutora em formação), além de demandar mais conhecimentos e mais reflexões sobre o funcionamento da linguagem.

Um terceiro desafio está associado à necessidade de mudar a visão que discentes em geral (e tradutores e tradutoras em formação, em específico) têm de si próprios/as e de como eles/as avaliam suas produções textuais. Ruiz (1998) chega a abordar essa mudança de paradigmas como uma possível revolução no ensino da língua no país. A autora defende enfaticamente a busca por "uma prática real, interpessoal, contextualizada de uso da língua, uma prática de ação intencional e recíproca, nessa mesma escola" (RuIz, 1998, p. 190), que reforce o papel do/a discente enquanto autor/a que busca encontrar sua voz e seus espaços como locutor/a, que interage com leitores/as e revisores/as e não mais como um/a aluno/a 
que "meramente cobre as próprias "faltas", denunciadas pelo "cartão amarelo", sempre a postos, do juiz-professor" (RUIZ, 1998, p. 191).

O último, mas não menos importante, desafio aqui apontado é a busca pela redução nas assimetrias entre tradutores e tradutoras em formação e revisores/as, de forma que as partes se integrem na produção de textos e se vejam como co-produtores/as de significados a partir dos textos traduzidos, aceitando críticas e sugestões de forma aberta e construtiva.

Após tantas referências ao trabalho de Ruiz (1998), nada mais justo que concluir com uma deferência à proposta da autora de busca por mais riscos no ensino, pois "[é] a ousadia do risco que pode nos mostrar a saída. E isso não se consegue sem uma dose de coragem, de otimismo, de boa-vontade, de idealismo, e de auto-confiança, principalmente" (RUIZ, 1998, p. 198).

\section{Referências}

COSTA VAL, M. da G. Texto, textualidade e textualização. In: CECCANTINI, J. L. T.; PEREIRA, R. F.; ZANCHETTA JR., J.. Pedagogia cidadã: cadernos de formação: Língua Portuguesa. v. 1. São Paulo: UNESP, Pró-Reitoria de Graduação, 2004. p. 113-128.

FERREIRA, M. G. di M. Autorreflexão sobre o processo de revisão de tradução a partir das atividades desenvolvidas no Projeto Revtrad. 2018. 50f. Trabalho de Conclusão de Curso (Bacharelado em Tradução), Universidade Federal da Paraíba, João Pessoa, 2018.

INTERNATIONAL Organization for Standardization. ISO. ISO 17100:2015. Translation services Requirements for translation services. International Organization for Standardization, 2015. Disponível em https://www.iso.org/standard/59149.html. Acesso em: 20 fev. 2020.

LEIPNITZ, L. "Befehlerles" versus "Comandantinhos" Comentários dos revisores da tradução. Revista Graphos, v. 18, n. 2, p. 177-181, 2016. Disponível em: http://www.periodicos.ufpb.br/ojs/index.php/graphos/article/view/32168/16712. Acesso em: 1 out. 2018.

HEWSON, L. An approach to translation criticism. Amsterdam/Philadelphia: John Benjamins, 2011.

MORAIS, A.; FERREIRA, A. Avaliação do texto escrito: uma questão de concepção de ensino e aprendizagem'. In: LEAL, T.; BRANDÂO, A.C., Produção de textos na escola: reflexões e práticas no Ensino Fundamental. 1ed., 1 reimp. Belo Horizonte: Autêntica, 2007.

MOSSOP, B., Editing and revising for translators. 2. ed. Manchester, Kinderhook: St. Jerome, 2007.

PACTE. Building a translation competence model. In: Alves, F. Eed.). Triangulating translation. Amsterdam, Philadelphia: John Benjamins, 2003, p. 43-66. 
PACTE. First results of a translation competence experiment: 'Knowledge of translation' and 'efficacy of the translation process'. In: KEARNS, J. (Ed.). Translator and interpreter training: issues, methods and debates. London: Continuum, 2008. p. 104-126.

RUIZ, E. Como se corrige redação na escola. 1998. 307 f. Tese (Doutorado em Linguística) Instituto de Estudos da Linguagem, Universidade Estadual de Campinas: Campinas, 1998. 